\title{
Does Affective
}

DisPOSITION

Moderate THE

ReLATIONSHIIP BE-

TWEEN JOB SATIS-

FACTION \& VOLUN-

TARY TURNOVER?

Working Paper 92-19

Timothy A. Judge 
Does Affective Disposition Moderate the Relationship Between

Job Satisfaction and Voluntary Turnover?

\author{
Timothy A. Judge \\ Center for Advanced Human Resource Studies \\ New York State School of Industrial and Labor Relations \\ Cornell University
}

Working Paper \# 92-19

$* * * *$

Manuscript Under Review:

$* * *$

Do Not Quote or Cite Without Permission

RUNNING HEAD: DISPOSITION, JOB SATISFACTION, AND TURNOVER

This paper has not undergone formal review or approval of the faculty of the ILR School. It is intended to make results of Center Research, conferences, and projects available to others interested in human resource management in preliminary form to encourage discussion and suggestions. 
Disposition, Job Satisfaction, and Turnover

\begin{abstract}
Weitz (1952) argued that job dissatisfaction would be more predictive of turnover if it was considered in light of an individual's predisposition to be satisfied with everyday life events. In the present study it was hypothesized that affective disposition moderates the relationship between job satisfaction and voluntary turnover. Using data collected from a sample of nurses, support was indicated for the hypothesis. Individuals dissatisfied with their jobs but positively disposed to their life in general were the most likely individuals to quit. Furthermore, the relationship between job dissatisfaction and turnover was moderately strong for those with "positive" dispositions but negligible for those with "negative" dispositions.
\end{abstract}




\section{Does Affective Disposition Moderate the Relationship Between Job Satisfaction and Voluntary Turnover?}

Empirical work over the years has clearly established that the role of job satisfaction in predicting turnover is significant. Carsten and Spector (1985), in a meta-analysis of 47 studies, estimated a corrected correlation between job satisfaction and turnover of -.26. Although this relationship was significant (the $95 \%$ confidence interval did not include 0 ), the authors concluded that room for significant moderator effects existed. In fact, Carsten and Spector (1985) found that alternative employment opportunities moderated the relationship between job satisfaction and turnover. Based on Carsten and Spector's (1985) findings, the potential exists that other variables interact with job satisfaction in predicting turnover. Given the importance of turnover decisions to individuals and organizations (Dalton \& Todor, 1979; Mobley, 1982; Staw, 1980; Staw \& Oldham, 1978; Steers \& Mowday, 1981), it is surprising that more research concerning potential moderators of the job satisfaction - turnover relationship have not been conducted.

A potential, but previously unstudied, moderator of the job satisfaction - turnover relationship was hypothesized by Weitz (1952). He argued that a worker's level of dissatisfaction might be more meaningful if placed in the context of the worker's predisposition to be satisfied in general. Rather than inferring that a certain level of dissatisfaction will induce turnover among all workers, Weitz (1952) argued that attempts to improve the prediction of turnover might benefit from considering the individual's disposition. He speculated that if two workers report the same level of dissatisfaction, the one most likely to quit is the one with the highest predisposition to be happy or satisfied in general. In order to measure this predisposition, Weitz (1952) proposed a "gripe index" which assessed satisfaction with 44 items prevalent in everyday life. These items ranged from the way people drive to income tax to the national political situation.

In essence, Weitz (1952) was hypothesizing an interaction between affective disposition and job satisfaction in predicting turnover. He suggested that "some individuals 
generally gripe more than others" (p. 203), and that such individuals, when dissatisfied with their job, are less likely to quit than those more positively disposed toward life. Weitz (1952) explained that this should be expected because an individual with a "positive" disposition reporting a certain level of job dissatisfaction is more dissatisfied relative to other things in his or her life than an individual with a "negative" disposition reporting the same level of job dissatisfaction. This also suggests that the relationship between job dissatisfaction and turnover is greater for generally satisfied than generally dissatisfied individuals, because for the generally dissatisfied (those with a "negative" disposition) dissatisfaction with the job is no more meaningful or exceptional than the other dissatisfying events in their lives. The possibility that affective disposition moderates the relationship between job satisfaction and withdrawal behaviors such as turnover was recently reinforced by Gerhart (1990b) and Smith (1992).

Mobley's (1977) psychological process model of turnover provides conceptual support for Weitz's (1952) hypothesis. Mobley (1977) argued that job dissatisfaction is translated into thoughts of quitting, evaluation of alternatives, and ultimately turnover because quitting is expected to result in a more satisfying job. However, those more negatively disposed toward life may have no such expectation. For them, job dissatisfaction simply may be another dissatisfying element in an already dissatisfying world. This is supported by research suggesting that job satisfaction may derive from genetic or early childhood influences (Arvey, Bouchard, Segal, \& Abraham, 1989; Staw, Bell, \& Clausen, 1986). Thus, for these individuals, job dissatisfaction and quitting may seem to have little to do with each other. Changing jobs may not result in higher satisfaction because the dissatisfaction is less due the characteristics of the job than to affective predispositions. On the other hand, job dissatisfaction is much more salient and generates more tension for generally happy individuals, and changing jobs may appear to be a viable means of correcting one of the few dissatisfying elements in their life. 
Thus, it is hypothesized in the present study that there is an interaction between affective disposition and job satisfaction in predicting turnover. Specifically, job dissatisfaction will be more predictive of turnover for generally satisfied individuals (i.e., those with a "positive" disposition) than generally dissatisfied individuals (i.e., those with a "negative" disposition). If this hypothesis is correct, one would expect to observe a higher correlation between job satisfaction and turnover for those with a "positive" disposition than for those with a "negative" disposition, and also that individuals with high job dissatisfaction and a "positive" disposition should exhibit higher turnover rates than other individuals.

Consistent with past research, it also is expected that job satisfaction be negatively associated with turnover. Furthermore, several relevant control variables identified by past research to be predictive of turnover were taken into account. These variables were age (Porter \& Steers, 1973), experience (Mobley, 1982), wage rates (Dalton \& Todor, 1979; Hellriegel \& White, 1973), education (Mellow, 1980), and labor market alternatives (Gerhart, 1990a; Miller, Katerberg, \& Hulin, 1979; Mobley, Horner, \& Hollingsworth, 1978).

\section{Method}

\section{Setting and Subjects}

The setting for this research was a medical clinic located in the Midwest. Subjects were registered nurses (59\%), licensed practical nurses (14\%), medical office assistants (16\%), and laboratory technicians or clinical specialists (11\%). Education of the respondents ranged from high school diploma (11\%) to master's degree (11\%). The average hourly wage rate was $\$ 9.60$, with a range of $\$ 4.15$ to $\$ 17.43(\underline{\mathrm{SD}}=\$ 4.15)$. Age ranged from 21 to 70 years, with an average age of 37.2 years $(\underline{S D}=9.2$ years). Job tenure ranged from newly employed to 50 years; the average level of tenure was 12.1 years $(\underline{\mathrm{SD}}=$ 7.9 years). Approximately $41 \%$ of respondents perceived little or no employment alternatives, $40 \%$ perceived some alternatives, and approximately $19 \%$ perceived many 
employment alternatives. The annualized average voluntary turnover rate for subjects in this sample was $17.9 \%$, which is close to the average turnover rate of the United States workforce (Mobley, 1982).

\section{$\underline{\text { Measures }}$}

Affective disposition. Affective disposition was measured by a scale derived from the measure developed by Weitz (1952). His 44-item scale consisted of a checklist of facially neutral objects. Weitz (1952) termed the scale a "gripe index" because individuals expressing a large number of dissatisfactions in their life, as measured by the checklist, may be predisposed to view most things negatively. Thus, the survey measures disposition by reflecting affective bias toward items common to everyday life. Individuals highly satisfied with the objects as a whole may have a Pollyannic tendency to see everything (including the job) in a favorable light. The obverse also is hypothesized to be true. Weitz (1952) reported a split-half reliability of .75 for the scale.

In the present study Weitz's checklist was modified in several ways. The modified 25 -item survey eliminates some "messy" measures of disposition. Items confounded with socioeconomic status (e.g., "the area of the city in which you live") and previous employment (e.g., "your last job"), and other items that would not apply to all individuals (e.g., "the college you attended") were excluded. Wording also was modernized (e.g., "automobile" was changed to "car"). The coefficient alpha reliability estimate for the revised scale was .78. The revised scale, termed the Neutral Objects Satisfaction Questionnaire, is contained in the Appendix.

Job satisfaction. Job satisfaction was measured by the Job Descriptive Index (JDI; Smith, Kendall, \& Hulin, 1969), as modified by Roznowski (1989). Overall job satisfaction can be represented by five facets: pay, promotion opportunities, supervision, co-workers, and the work itself. The intercorrelations of those facets reveal a communality among the dimensions, suggesting a second-order general factor (Parsons \& Hulin, 1982). In the present study, the reliabilities of the JDI subscales ranged from .85 to .91 . 
Voluntary turnover. Data on voluntary turnover was gathered from company records 10 months after surveys were completed by the respondents. Company representatives were asked to indicate which separations were voluntary and which were not.

Other variables. Alternative employment opportunities were assessed by asking the individual to estimate their alternative employment opportunities at the present time $(1=$ no alternatives; 5 = many alternatives). Age, wage rate, job tenure, and highest education level achieved also were measured from specific questions on the survey. $\underline{\text { Procedure }}$

The questionnaire data collected for this study were part of a larger study which served as the basis for the dissertation of the author (Judge, 1990). Surveys were administered to employees on a voluntary basis during their work hours. Scheduling was coordinated by department supervisors. Employees were gathered in small group sessions (15-20 individuals) where the purpose of the study was explained and employees were asked (but not required) to participate. Confidentiality of individual responses was assured, and feedback on the results of the survey was promised and subsequently delivered. Two hundred and fifty-five employees signed up and completed usable surveys, representing a response rate of approximately $80 \%$. Follow-up conversations with department supervisors suggested that those not participating were either on leave or unavailable for other reasons beyond their control. Turnover data was collected after completion of the author's dissertation. Due to listwise deletion of variables with missing values and exclusion of involuntary terminations, 234 observations were available for the analysis.

\section{Results}

In order to insure that using the facets of the JDI to form an overall measure of job satisfaction was warranted, confirmatory factor analysis was conducted (Joreskog \& Sorbom, 1989; Long, 1983). The fit indices from the confirmatory factor analysis revealed 
that the facets could be combined into an overall construct (chi-square $=3.27$ with 5

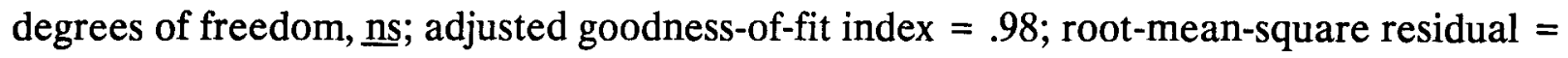
.02; see La Du \& Tanaka, 1989, and Marsh, Balla, \& McDonald, 1988, for a review of these indices). The confirmatory factor analysis revealed the following factor weights: JDI-work $=.61 ; \mathrm{JDI}$-supervision $=.64 ; \mathrm{JDI}$-coworkers $=.45 ; \mathrm{JDI}$-pay $=.33 ; \mathrm{JDI}$-promotion $=.36$. These weights were used in adding the subscales to form an overall measure of job satisfaction. Using unitary weights yielded equivalent results.

In order to facilitate interpretation of the interaction, the measures of affective disposition and job satisfaction were dichotomized. Individuals scoring above the mean of the affective disposition scale were classified as members of one group (e.g., "positive" disposition), and individuals scoring below the mean were classified as members of the other group (e.g., "negative" disposition). An identical procedure was repeated with respect to job satisfaction. Analysis of variance (ANOVA) was used as the method of analysis. The typical procedure of entering covariates (all control variables) first, then adding the main effects, and finally entering the interaction term, was followed.

The ANOVA results are presented in Table 1. As the table indicates, job satisfaction exerted a significant main effect on turnover. This effect can be illustrated by the fact that the turnover rate for individuals more satisfied than average with their jobs was .09. The turnover rate for those less satisfied than average with their jobs was .22. As hypothesized, the interaction between affective disposition and job satisfaction was significant. The interaction is graphically represented in Figure 1. The figure illustrates that the average turnover rate for individuals who were more satisfied than average with their jobs and had a "positive" disposition was $.07(\underline{n}=85)$. The average turnover rate for individuals who were more satisfied than average with their jobs and had a "negative" disposition was $.11(n=44)$. The average turnover rate for individuals who were less satisfied than average with their jobs and had a "positive" disposition was $33(\underline{n}=45)$. The average turnover rate for individuals who were less satisfied with their jobs and had a 
"negative" disposition was $.13(\underline{n}=60)$. Finally, the correlation between job satisfaction and turnover for individuals with a "positive" disposition was $-.39(\mathrm{p}<.01)$. The correlation between job satisfaction and turnover for those with a "negative" disposition was -.05 (ns).

Insert Table 1 and Figure 1 About Here

The effect of the variables on turnover also was estimated using the continuous rather than dichotomized measures of affective disposition and job satisfaction. Using ridge regression to correct for problems generated by multicollinearity between the interaction term and the main effects (Lin \& Kmenta, 1982), the interaction term remained significant in this estimation $(\mathrm{t}=-2.00 ; \mathrm{p}<.01)$. When entering the interaction in a hierarchical moderated regression analysis, the interaction explained $2.9 \%$ of the variance in turnover $(p<.01)$ over and above the effect accounted for by the other variables.

\section{Discussion}

The present study provided support for Weitz's (1952) hypothesis that affective disposition moderates the relationship between job satisfaction and voluntary turnover. Specifically, employees with a "positive" disposition who were dissatisfied with their jobs were much more likely to quit than other individuals. Equivalently, job satisfaction and voluntary turnover were more highly related for employees with "positive" dispositions than for employees with "negative" dispositions. Several factors may explain why this relationship was observed.

First, it is possible that a dissatisfying element of life is more salient, and alarming, for individuals who are generally satisfied than for those who are generally dissatisfied. Some research from the performance appraisal area suggests that individuals are more likely to attend to information that is inconsistent with their expectations (Balzer, 1980). Consistent with Mobley's (1977) process model, such attention may provoke the individual 
to consider alternatives to their current work role. This suggests that individuals with "positive" dispositions who are dissatisfied with their jobs are most likely to quit because the job dissatisfaction is inconsistent with their positive expectations about life, and thus arouses their attention to work role alternatives that ultimately result in quitting. In presenting a model of behavioral responses to job dissatisfaction, Fisher and Locke (1992) suggested that those negatively disposed toward life are less likely to translate job dissatisfaction in withdrawal behaviors than other individuals. Thus, job satisfaction and turnover may be unrelated for those with a "negative" disposition because these individuals are not accustomed to acting based on their levels of job dissatisfaction. Conversely, Fisher and Locke (1992) suggested that individuals equally dissatisfied with their jobs, but more positively disposed toward life, may be quite active in changing their work situation.

A related possibility, and probably one closer to Weitz's (1952) reasoning, is that assessing affective disposition permits a more accurate assessment of the true job dissatisfaction of the individual relative to other things in his or her life. Individuals may act on dissatisfaction with a specific object only when it surpasses some relative internal standard. Generally dissatisfied individuals who report dissatisfaction with their jobs are reporting an average internal level of satisfaction. Conversely, generally satisfied individuals reporting the same level of job dissatisfaction are reporting a much higher degree of dissatisfaction with their jobs relative to other concerns in their life. Thus, by accounting for the satisfaction predisposition of individuals, we obtain a more accurate measurement of the relative degree of job satisfaction or dissatisfaction. As a result, higher relations with turnover are observed.

A third possibility derives from past dispositional research. Staw and Ross (1985) and Staw et al. (1986) have suggested that changes in job conditions may be constrained by dispositional forces. As Gerhart $(1987,1990 \mathrm{~b})$ pointed out, this implies a dispositional interaction. The interaction found in the present study may indicate that the potentially adaptive nature of turnover is less for those with a "negative" disposition. Because those 
with a "negative" disposition are generally dissatisfied with the world around them, changing the conditions of the job may do little to change this generalized state. As Staw and Ross (1985) pointed out, disposition may affect how individuals rationalize difficult or dissatisfying job conditions. Thus, those with a "negative" disposition may fail to take action as a result of job dissatisfaction through beliefs that one cannot improve one's life for the better, that a job is simply a means to earn a living and nothing more, and other such cynical rationalizations (Kanter \& Mirvis, 1989).

A final potential explanation of the results of the present study concerns the possibility of a response set. It is possible that the neutral objects questionnaire measures the propensity to use a response set in completing the JDI. Once the response set is taken into account, a more valid measure of the job satisfaction construct is obtained (i.e., "true" levels of job satisfaction are measured taking into account the artifact of individuals' response tendencies), and hence the ability of job satisfaction to predict turnover is enhanced (see Gerhart, 1990b). If this interpretation is correct, the practical implication is that before attitudes are related to behaviors such as turnover, attitude measures should be adjusted for response tendencies (Gerhart, 1990b; Guilford, 1954).

However, past research on the JDI casts some doubt on this interpretation. As documented by Smith et al. (1969), the JDI has not been shown to be affected by response sets. Furthermore, using item response theory, Drasgow and Hulin (1990) indicated that items in the JDI have a very high ability to discriminate among individuals with respect to their "true" level of job satisfaction. This suggests that most items are not subject to response sets. In sum, regardless of which of these explanations are correct, all four are consistent with the hypothesized result and thus provide conceptual support to explain the statistical effect.

The results of this study suggest implications for practice and future research. The results indicate that affective disposition is an important construct to consider when one is interested in the prediction of turnover. If these results generalize, the effect of job 
satisfaction on turnover depends on the propensity of employees to be satisfied in general. To employees unhappy with most things in their life, job dissatisfaction is not a particularly important factor in decisions to quit, and these employees are less likely to quit when dissatisfied with their jobs. On the other hand, job dissatisfaction is a significant factor in turnover decisions to employees with a "positive" disposition. As Weitz (1952) maintained, the importance of job dissatisfaction to turnover depends on the general disposition of the individual.

The results provide more supportive evidence regarding the efficacy of the dispositional approach in explaining attitudes and behaviors in organizations. Future research, using a different samples of workers, is needed to replicate the interaction between affective disposition and job satisfaction in predicting turnover. If the results are replicated, then it would seem useful to investigate if the interaction applies to other behaviors, or to the behaviors cumulatively. For example, Judge and Hulin (1991) found that a number of withdrawal behaviors displayed sufficient covariation to represent a common construct. Finally, research is needed to investigate directly the psychological explanations reviewed above that might account for the effect observed. 
Disposition, Job Satisfaction, and Turnover

\section{References}

Arvey, R.D., Bouchard, T.J., Segal, N.L., \& Abraham, L.M. (1989). Job satisfaction: Environmental and genetic components. Journal of Applied Psychology, 74, 187192.

Balzer, W.K. (1986). Biases in the recording of performance-related information: The effects of initial information and centrality of the appraisal task. Organizational Behavior and Human Decision Processes, 37, 329-347.

Dalton, D.R., \& Todor, W.D. (1979). Turnover turned over: An expanded and positive perspective. Academy of Management Review, 4, 225-235.

Drasgow, F., \& Hulin, C.L. (1990). Item response theory. In M.D. Dunnette \& L.M. Hough (Eds.), Handbook of industrial and organizational psychology (2nd ed., Vol. 1, pp. 577-636). Palo Alto, CA: Consulting Psychologist Press.

Fisher, C., \& Locke, E.A. (1992). The new look in job satisfaction theory and research. In J. Cranny, P. Smith, \& E.F. Stone (Eds.), Job satisfaction: How people feel about their jobs and how it affects their performance (pp. 165-194). New York: Lexington Books.

Gerhart, B. (1987). How important are dispositional factors as determinants of job satisfaction? Implications for job design and other personnel programs. Journal of Applied Psychology, 72, 366-373.

Gerhart, B. (1990a). Voluntary turnover and alternative job opportunities. Journal of Applied Psychology, 75, 467-476.

Gerhart, B. (1990b). What is the practical relevance of dispositional effects on job satisfaction? Working paper \#90-06, Center for Advanced Human Resource Studies, Cornell University.

Guilford, J.P. (1954). Psychometric methods. New York: McGraw-Hill.

Hellriegel, D., \& White, G.R. (1973). Turnover of professionals in public accounting: A comparative analysis. Personnel Psychology, 26, 239-249. 
Joreskog, K.G., \& Sorbom, D. (1989). LISREL 7: A guide to the program and applications. Chicago: SPSS Inc.

Judge, T.A. (1990). Job satisfaction as a reflection of disposition: Investigating the relationship and its effect on employee adaptive behaviors. Unpublished doctoral dissertation, University of Illinois at Urbana-Champaign.

Judge, T.A., \& Hulin, C.L. (1991). Job satisfaction and subjective well-being as influences on employee withdrawal. Working Paper \#91-10, Center for Advanced Human Resource Studies, Cornell University.

Kanter, D.L., \& Mirvis, P.H. (1989). The cynical Americans: Living and working in an age of discontent and disillusion. San Francisco: Jossey-Bass.

La Du, T.J., \& Tanaka, J.S. (1989). Influence of sample size, estimation method, and model specification on goodness-of-fit assessments in structural equation models. Journal of Applied Psychology, 74, 625-635.

Lin, K., \& Kmenta, J. (1982). Ridge regression under alternative loss criteria. Review of Economics and Statistics, 64, 488-494.

Long, J.S. (1983). Covariance structure models: An introduction to LISREL. Beverly Hills: Sage.

Marsh, H.W., Balla, J.R., \& McDonald, R.P. (1988). Goodness-of-fit indexes in confirmatory factor analysis: The effect of sample size. Psychological Bulletin, 103, 391-410.

Mellow, W. (1980). A multinomial logit model of labor turnover. Journal of Economics and Business, 32 , 227-234.

Miller, H.E., Katerberg, R., \& Hulin, C.L. (1979). Evaluation of the Mobley, Horner, and Hollingsworth model of employee turnover. Journal of Applied Psychology, 64, 509517.

Mobley, W.H. (1977). Intermediate linkages in the relationship between job satisfaction and employee turnover. Journal of Applied Psychology, 62, 237-240. 
Mobley, W.H. (1982). Employee turnover: Causes, consequences, and control. Reading, MA: Addison-Wesley.

Mobley, W.M., Horner, S.O., \& Hollingsworth, A.T. (1978). An evaluation of precursors of hospital employee turnover. Journal of Applied Psychology, 63, 408-414.

Parsons, C.K., \& Hulin, C.L. (1982). An empirical investigation of item response theory and hierarchical factor analysis in applications to the measurement of job satisfaction. Journal of Applied Psychology, 67, 826-834.

Porter, L.W., \& Steers, R.M. (1973). Organizational, work, and personal factors in

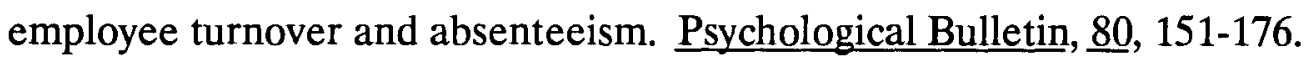

Roznowski, M. (1989). An examination of the measurement properties of the job descriptive index with experimental items. Journal of Applied Psychology, 74, 805814.

Smith, P.C. (1992). In pursuit of happiness: Why study general job satisfaction? In J. Cranny, P. Smith, \& E.F. Stone (Eds.), Job satisfaction: How people feel about their jobs and how it affects their performance (pp. 5-19). New York: Lexington Books.

Smith, P.C., Kendall, L., \& Hulin, C.L. (1969). The measurement of satisfaction in work and retirement. Chicago: Rand McNally.

Staw, B.M. (1980). The consequences of turnover. Journal of Occupational Behavior, 1 , 253-273.

Staw, B.M., \& Oldham, G.R. (1978). Reconsidering our dependent variables: A critique and empirical study. Academy of Management Journal, 21, 539-559.

Staw, B.M., \& Ross, J. (1985). Stability in the midst of change: A dispositional approach to job attitudes. Journal of Applied Psychology, 70, 469-480.

Staw, B.M., Bell, N.E., \& Clausen, J.A. (1986). The dispositional approach to job attitudes: A lifetime longitudinal test. Administrative Science Quarterly, $\underline{31}$, 56-77. 
Steers, R.M., \& Mowday, R.T. (1981). Employee turnover and post-decision accommodation process. In L.L. Cummings \& B.M. Staw (Eds.), Research in organizational behavior (Vol. 3, pp. 235-281). Greenwich, CT: JAI Press.

Weitz, J. (1952). A neglected concept in the study of job satisfaction. Personnel Psychology, $\underline{5}, 201-205$. 
Appendix

Neutral Objects Satisfaction Questionnaire

DIRECTIONS: The following questions ask about your degree of satisfaction with several items. Consider each item carefully. Circle the numbered response that best represents your feeling about the corresponding item.

\section{Dissatisfied Neutral $\underline{\text { Satisfied }}$}

1. The city in which you live

2. The residence where you live

3. The neighbors you have

4. The high school you attended

5. The climate where you live

6. The movies being produced today

7. The quality of food you buy

8. Today's cars

9. Local newspapers

10. Your relaxation time

11. Your first name

12. The people you know

13. Television programs

14. Local speed limits

15. The way people drive

16. Advertising

17. The way you were raised

18. Telephone service

19. Public transportation

20. Restaurant food

21. Yourself

22. Modern art

23. Popular music

24. $81 / 2^{\prime \prime} x 11$ " paper

25. Your telephone number

$\begin{array}{lll}1 & 2 & 3\end{array}$

$\begin{array}{lll}1 & 2 & 3\end{array}$

$1 \quad 2 \quad 3$

123

123

$\begin{array}{lll}1 & 2 & 3\end{array}$

$\begin{array}{lll}1 & 2 & 3\end{array}$

$1 \quad 2 \quad 3$

$\begin{array}{lll}1 & 2 & 3\end{array}$

123

123

123

$1 \quad 2 \quad 3$

$1 \quad 2 \quad 3$

123

123

123

$1 \quad 2 \quad 3$

123

123

123

$\begin{array}{lll}1 & 2 & 3\end{array}$

$1 \quad 2 \quad 3$

$\begin{array}{lll}1 & 2 & 3\end{array}$

123


Disposition, Job Satisfaction, and Turnover

\begin{abstract}
Author Notes
The author thanks Charles Hulin for his contributions to this project, and Bob Bretz and Barry Gerhart for comments on an earlier version of this manuscript. Correspondence regarding this article may be addressed to Timothy A. Judge, Department of Personnel and Human Resource Studies, Cornell University, 393 Ives Hall, Ithaca, New York 14853-3901.
\end{abstract}


Table 1

\section{Analysis of Variance Results}

\begin{tabular}{|c|c|c|c|}
\hline Source & $\begin{array}{l}\text { Sum of } \\
\text { Squares }\end{array}$ & DF & $\mathbf{F}$ \\
\hline \multicolumn{4}{|l|}{ Covariates } \\
\hline Alternative Employment opportunities & 0.083 & 1 & 0.703 \\
\hline Education & 0.044 & 1 & 0.371 \\
\hline Age & 0.033 & 1 & 0.283 \\
\hline Job Tenure & 0.056 & 1 & 0.475 \\
\hline Wage Rate & 0.105 & 1 & 0.892 \\
\hline \multicolumn{4}{|l|}{ Main Effects } \\
\hline Job Satisfaction (JS) & 1.059 & 1 & $9.002^{* *}$ \\
\hline Affective Disposition (AD) & 0.182 & 1 & 1.548 \\
\hline \multicolumn{4}{|l|}{ Interaction } \\
\hline$J S \times A D$ & 0.852 & 1 & $7.241^{* *}$ \\
\hline Explained & 2.598 & 8 & $2.761^{* *}$ \\
\hline Residual & 26.462 & 225 & \\
\hline Total & 29.060 & 233 & \\
\hline
\end{tabular}

Note: $* * \underline{p}<.01$ 
Disposition, Job Satisfaction, and Turnover

\section{Figure Caption}

Figure 1. Interaction of Affective Disposition and Job Satisfaction in Predicting Turnover. 


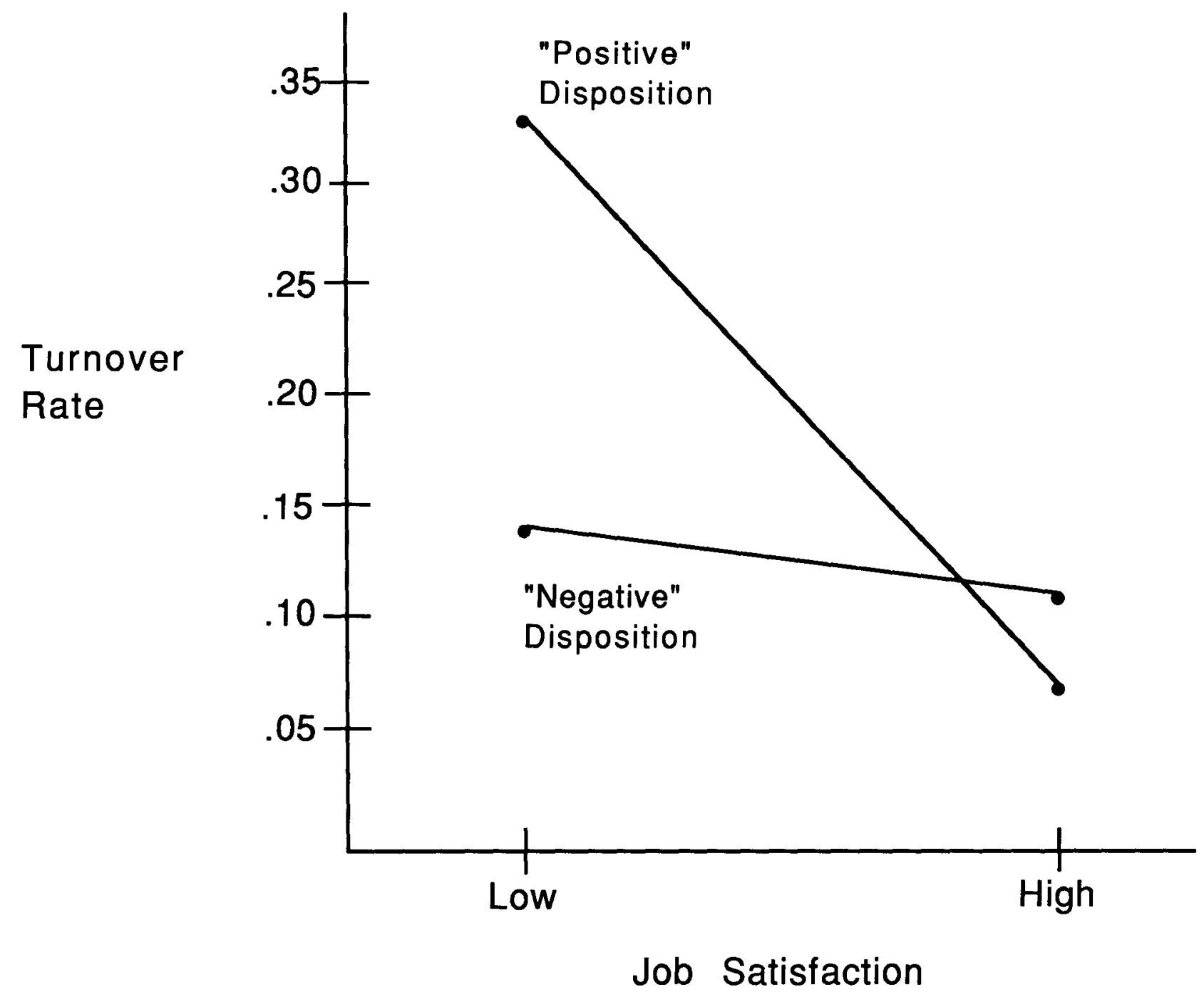

